\title{
Administrative Supervision and Information Relationships
}

\author{
Victor Bekkers and Vincent Homburg \\ Erasmus University Rotterdam \\ Faculty of Social Sciences \\ Public Administration G roup \\ PO Box 1738 \\ 3000 D R Rotterdam \\ The Netherlands \\ Phone: +(31) 104082133 \\ Email: \{bekkers, homburg\}@ fsw.eur.nl
}

\section{SUMMARY}

In many countries, administrative supervision has grown dramatically in recent years. A dministrative supervision is a form of interaction between policy makers and policy ex ecutors, aimed at improving political accountability. In this paper, the role of information and information relationships between policy making bodies, ex eative institutions and administrative supervisors is ex plored. W e identify three roles of administrative supervisors: a dassical (op) role, a modern (coach) role, and a networking (director) role. E ach role has requirements with respect to the information relationship, particularly in the relationship between the supervisory authority and the ex ecutive institution. In this paper, we analyze the sometimes contradictory roles of administrative supervisors and the implications for information relationships, and we indicate the consequences for practice.

Key words: supervisory authorities, administrative supervision, information relationships 


\section{INTRODUCTION}

Increasingly in the public sector, policy making is organizationally separated from policy execution [1, 2]. Sweden has about 300 agencies executing policy. In Japan, 84 independent administrative agencies exist and in the United Kingdom, 140 agencies either deliver services to the public or have a regulatory role. In the Netherlands, more than 600 independent administrative bodies execute policies in the fields of social security, housing, public health, et cetera, on behalf of policy making body. Furthermore, many municipalities are involved in the execution of delegated tasks on behalf of national policy making bodies.

Examples of policy areas in the Netherlands in which policy making and policy execution are separated, are: the execution of national Student Loan Schemes by the executive institution 'IB G roep' and the provision of building permits by municipalities based on building legislation by the Ministry of Housing, Spatial Planning and the Environment.

The notion of separating policy execution is a part of a cluster of ideas, ranging from cutting down 'red tape', financial transparency, decentralization of authority, the use of performance indicators and the creation of market-like mechanisms in government. This cluster of ideas is often labeled new public management (NPM).

NPM in general, and the autonomization of policy execution in particular, raises fundamental questions of political control and political accountability in policy networks of public sector organizations 1 It is believed that the separation of policy making and policy execution, and the emergence of policy networks instead of unitary bureaucracies, decreases the traditional control over policy execution by policy makers and intensifies the need for explicit accountability requirements to be imposed on executive institutions. Hood et al conclude that because of what they refer to as recent preoccupations with rolling back bureaucracy, putting agencies at arm's length and empowering public sector managers, there seems to be a growing emphasis on accountability achieved through auditing, inspection, licensing and so forth [3]. Accountability requirements can be viewed as means to achieve political accountability, but also as means to achieve quality assurance in a policy process as a whole, and as an instrument to emphasize enforcement as the final element of a chain of policy processes.

An instrument which has been increasingly emphasized for promoting accountability is administrative supervision or administrative surveillance. In the above context, we define administrative supervision as the interaction between a policy making body or an independent supervisory body (or supervisory authority) on the one hand and an executive institution on the

\footnotetext{
${ }^{1}$ In this context, there is a striking parallel with the private sector, where the notion of corporate governance is being discussed both in theory as well as in practice.
} 
other hand, which is aimed at gathering information on how a policy is executed, evaluating and possibly adjusting by issuing sanctions (Figure 1). Hood et al add the condition of legality (the supervisor is required to have an official mandate to supervise and to change the supervised organization's behavior) [3].

In the remainder of this paper, we ask what role information and information relationships play in the context of administrative supervision, and analyze the soundness of exchanges of information between supervisory authorities and executive institutions. This question is relevant for a number of reasons.

First, it is interesting to note that the increased attention for administrative supervision is often described in conjunction with trends emphasizing political and public accountability. In a D utch policy document, for example, it is stated that information is important in processes of administrative supervision, and that it is necessary to specify and formalize information relationships in information statutes and information protocols as much as possible: "[i]f political responsibility is to be affected in practice, then the minister should be able to gather information in order for him to decide upon appropriate action (...) Monitoring and detection of possible risks should be undertaken in a timely fashion and the information relationships should be handled adequately" [4]. Bekkers has shown that in many policy networks, a cybernetic view of information relationships dominates $[5,6]$.

Second, the (partly) newly developed relationships between policy making bodies, supervisory authorities and executive institutions compel actors to think about the kind of institutional rules which should be used in the interaction (including the exchange of information) between policy makers and executive institutions. This aspect relates to the fact that information relationships are part of general administrative relationships between institutions and that matters of institutional trust, for example, are relevant.

Third, the availability of both information technologies (the means to store and analyze data) as well as well as communication technologies (the means to gather, exchange and disperse information) has become widespread and thus there is a potential for developing interorganizational information systems [7, 8] in administrative supervision practice. As has been mentioned earlier, information and communication technologies enable the properties of calculation and transaction, transparency, communication and interaction and even visualization through the use of virtual reality techniques in policy processes.

In order to answer the research questions mentioned above, we first turn to the concept of administrative supervision and the ideal typical roles supervisory authorities can play (Section 2). Subsequently, information relationships in the context of each role are described and the critical success factors and political risks of information relationships are identified (Section 3). Section 4 provides an analysis of cases of administrative supervision in the Dutch public sector. Conclusions are provided in Section 5. 


\section{AdMinistrative SUPERVISION}

\subsection{A Preliminary Demarcation}

Administrative supervision has grown dramatically in the past two decades. Various forms of administrative supervision can be discerned in the literature, so a demarcation must be made.

An important part of the increase in administrative supervision (Power even talks about the 'audit explosion' [9]) has taken place because of the emergence of audit and regulatory bodies acting as guard dogs with respect to the functioning of newly liberalized markets (and thus, with respect to, for example, telecom companies and financial institutions). Another category is represented by regulators that promote compliance of companies and citizens, for example with environmental legislation (an activity that is often referred to as 'enforcement'). This type of supervisory authorities is not analyzed in detail. We limit ourselves to supervisors that operate purely within the public sector.

But even within the public sector, various types of administrative supervisors can be distinguish and Hood et al have concluded that there is a sharp increase in organizations that are concerned with 'regulation-inside-government' [3]. Within this category, in this article, we do not focus on supervisors who scrutinize both policy making bodies and policy executing institutions (like Courts of Audit). Rather, we study the type of supervision by or on behalf of policy making bodies with respect to institutions that execute policies. In general, in this specific context, administrative supervision of and accountability for executive public organizations is aimed at increasing the transparency of policy processes. In order to do this, information has to be exchanged between one or more policy making bodies, one or more supervisory authorities and executive institutions (and, eventually, parliament). The necessity of information exchange, and the underlying 'quest' for transparency, raises questions with respect to the potential of information and communication technologies (ICTs) because it has been argued that ICTs are capable of increasing transparency [6], stimulating openness of government and enhancing interorganizational cooperation spanning various administrative agencies [10].

Thus, in this article, we assume that the ultimate aim of administrative supervision is to promote transparency, in order to enable politicians (and public managers acting on their behalf) to form their own opinion as to the quality of the execution of tasks practiced by the executive organizations in question. Information regarding the quality of the execution can be obtained either by supervising the performance of the statutory tasks in question by policy making bodies, or by arranging for a third party (an independent supervisory authority) to exercise supervision on behalf of policy making bodies.

\subsection{Roles of Supervisory Authorities}


In this article, we view administrative supervision in the context of steering (in networks of organizations). Although the descriptions and demarcations of supervisory authorities presented above seem to indicate a more or less precise conception of supervisory authorities and their activities, it is possible to identify a variety of roles supervisory authorities can perform [11, 12], just like there is a variety of steering modalities in networks of organizations [5].

\subsubsection{Administrative Supervision and Steering}

In general, activities of governments can be characterized in terms of planning, policy making and policy execution, and administrative supervision is also a part of these activities; moreover, it is a form of steering. Steering can be defined as a form of intended control within a particular context [13]. Supervisory authorities, likewise, attempt to monitor and possibly change the way policy is executed by an executive institution, and they do this on behalf of a policy making body. If administrative supervision is seen as a form of steering, this raises questions with respect to the particular context in which steering takes place. In this paper, three different contexts are explored.

The first one is a 'classical' context [5, 14]. In a classical context, supervisory authority has a classical role, and the basis for steering is a planning and control-like approach in which an omnirational central institutional actor attempts to influence its environment. The basic belief here is that the more information such a central actor possesses, the better it can plan, monitor and control.

The second one is a 'modern' context. This context and role more or less originated in criticism of the plan and control fallacy. Rather than controlling in a distant manner, a modern context assumes 'Vernetzung', i.e. intertwinement between government and society and between various government organizations. Steering does not take the form of planning and controlling the outside world, but rather influencing the interdependencies and organizational boundaries of various organizations.

The third one is a 'network' context. This context stretches the modern context a bit more, and assumes that government itself is positioned within society. The way to steer is to change interdependencies in the network it is part of itself, and change the formation of networks by inviting third parties to join the network thereby attempting to establish checks and balances.

In the next three subsections, the three roles of supervisory authorities are derived from the various steering contexts.

\subsubsection{Classical Role}


The first role of a supervisory authority is a classical role which relates to the classical context. This role more or less represents intergovernmental relationships in the 19th century when the emphasis was on a strict and explicit definition of duties and responsibilities of government [12], and on a uni-centric form of democracy in which all public authorities were ultimately accountable to parliament for their actions. In essence, in this role, the executive institution is principally subordinate to the policy making body (the political principal), and may demonstrate deviant behavior in practice which requires correction.

In a classical role, also referred to as 'supervision by screening', there is a clear separation of tasks between (1) supervisory authority and (2) executive institution ([11, 12]; see also [5]). The objective of the supervisory authority is to (incidentally) correct those situations which do not conform to specified norms. The supervisory authority does not have any executive tasks of its own, but merely observes, gathers information, compares observations with norms, and intervenes (sanctions) or has another authority (for example, a policy making body) intervene.

Relevant questions for the supervisory authority in a classical role are (see also [4]):

- D D oes the executive institution function conform to the legal norms?

- Does the executive institution function conform to general norms like equity before the law, et cetera, and is this reflected in periodical and systematic measurements?

- $\quad$ Does the executive institution function properly in terms of internal, financial management?

Essential for the supervisory authority in a classical role is that it is an enabler of political accountability in a chain, linking the execution of policies by executive institutions through policy making bodies, and ending in accountability to politicians in parliament. Duties and responsibilities in various links in the chains are separated, and sanctioning is predominantly repressive (e.g., dismissing and/ or replacing executives of, for example, executive institutions). Administrative supervision in a classical model is furthermore characterized by a lack of mutual empathy and a quest for control, compliance and obedience [15].

The metaphor that may be used to describe the supervisory authority in its classical role is the metaphor of the 'cop' or 'police office' (an enforcer of the law).

\subsubsection{Modern Role}


A second role of a supervisory authority is a 'modern' role which relates to the modern context. In a modern role, activities of the supervisory authority and the executive institution are intertwined. The interaction between these two organizations can vary in terms of intensity and frequency, and there is a close relationship between the tasks of the organizations involved. The quality of how a policy is executed is a joint responsibility of the executive institution and the supervisory authority (which is a clear departure from the 'classical' role of supervision by screening). Norms are neither static nor explicit, and are aimed at the quality of the policy as a whole (instead of the execution of a specific piece of legislation). Rather than supervision by screening, this form of administrative supervision can be described as 'supervision-by-steering'.

In a modern role, a supervisory authority can execute tasks that are adjacent to or overlapping with tasks of the executive institution, and duties and responsibilities may be intertwined. According to this role, there should not be too large a gap between the policy making body, supervisory authority and executive institution. In general, classical administrative supervision's basic assumptions of distrust, control and obedience are replaced by mutual professional respect and remoteness [15]. Norms and standards used in a modern role are not static, but situational and subject to negotiation between supervisory authority and executive institution. The metaphor which can most adequately describe this role is the metaphor of the 'coach' or 'consultant' [16].

\subsubsection{Network Role}

A third role of a supervisory authority is a 'networking' (or postmodern) role. Essential to the network role is the assumption that the political chain of command is not the only forum for accountability. Rather, it is assumed that various arenas exist in which, for example, executive institutions are held accountable for how they execute their (public) tasks. For example, a school may be asked to account for the way they execute tasks (1) to a ministry of education or an educational inspectorate with respect to conformance to educational goals, (2) to (regional or national) safety boards with respect to safety (3) to (regional or national) environmental agencies with respect to environmental aspects and (4) to parents who have sent their children to the school (or, in general: to the buyers of services rendered by the executive institution). This fictitious example shows that there are often various arenas in which an executive institution has to account for its actions.

In general, in the networking role, the emphasis is not on accountability per se, but rather on the creation of 'checks and balances' in the field of the executive institution, and on the creation of productive competition and co-operation between various supervisory authorities. For example, with respect to specific topics, executive institutions may experience that various supervisory authorities operate in adjacent or even slightly overlapping tasks. In the networking role, supervisory authorities may either (1) enter into a form of (productive) competition in which they compete with one another and try to render the 'best' supervision services to the 
policy making body (political principal) or (2) create 'checks and balances' between various executive institutions or between executive institutions and the public to which services are rendered. For example, an environmental supervisory authority may publish the environmental performance of a municipality, thereby attempting to influence the general public to raise their voice. Thus, 'naming and shaming' is an important feature of postmodern supervision. Websites on the World Wide Web have proved to be an interesting medium for exposing the performance of executive institutions. In both cases, it should be clear that the principal role of a supervisory authority is to constitute a network, or, to speak in terms of Rhodes [17], to regulate relationships in a complex system.

\subsubsection{Organizational Learning in Administrative Supervision}

Apart from the differences in orientation or even metaphor used to describe them, the roles can also be distinguished by referring to the type of (inter)organizational learning that takes place. In a classical role, the actual performance of an executive institution is confronted with relatively static norms, and if a significant deviation is noted, corrective measures are taken by the supervisory authority. This type of behavior can be classified as single loop learning.

In modern style administrative supervision, norms are ambiguous, and in negotiations between supervisory authority and executive institutions, the underlying policy assumptions of the executive institution are questioned. Such a form of learning has many characteristics of double loop learning.

The learning style of the network role, moreover, is based on the feature of connectivity in a network [18]. Supervisory authorities activate network participants (which may be other supervisory authorities, or groups of citizens acting as a supervisory authority) by means of sharing or combining information. Hence, connectivity here is the basis for organizational learning in a network.

The roles of supervisory authorities are summarized in Figure 2.

\section{INFORMATION RELATIONSHIPS: CRITICAL SUCCESS FACTORS AND RISKS}

\subsection{Introduction}


In responding to incidents regarding administrative supervision, the Dutch Minister of the Interior said: "Take a look at information and information gathering [...] We treat information as if it is to be written down and submitted in order to be filed in a file cabinet. It should be treated as an information agenda. [...] We in the public sector are working with outdated methods and institutional structures. But we have reached an era in which information and openness of information should affect our work in a qualitative way" [19]. This quotation raises questions regarding the formation of information relationships in the various roles of administrative supervision mentioned previously. With information relationships, we refer to sets of agreements regarding how information is exchanged in the context of administrative supervision, including agreements on quality control mechanisms.

Based on the discussion of the various roles of administrative supervisors above, it is now possible to analyze the information relationships that occur in any of the (ideal-typical) roles presented so far.

\subsection{Critical Success Factors in Information Relationships of Various Supervisory Roles}

In a classical role, the information relationship between supervisory authority and executive institution should reflect clarity and lack of ambiguity. The relationship should be clearly formalized and based on legislation, and this should include a clear demarcation and description of duties and responsibilities. If there is more than one supervisory authority, the duties and responsibilities of the various authorities should be clearly demarcated and formalized. In general, the information relationships are based on an in-depth information requirements analysis, and it is clear at what moments in time specific information is exchanged in the relationship, and to what kind of norms the exchanges should conform. These properties can be formalized in information statutes or information protocols.

In general, an information relationship in a classical role reflects the characteristics of a classical bureaucratic arrangement, with an emphasis on clarity and robustness (see Figure 3).

In a modern role, moreover, it is explicitly acknowledged that the interaction between supervisory authority and executive institution has a dynamic, continuous and more or less unpredictable character [5,12]. Therefore, the focus is not so much on robustness, but on flexibility. In relation to the information relationship, this implies that the exchange of information is continually subject to intergovernmental negotiation. In order to make this work, however, certain requirements must be observed. First, there is the requirement of (a perception of) equality of position in the relationship between the supervisory authority and the executive institution. Second, the parties involved should acknowledge each other's professionalism. Third, the availability of mutually acknowledged systems of certification is required to stimulate a certain amount of self regulation at the executive institution (see Figure 4). 
In a network role, the focus is not primarily on the interaction between supervisory authority and executive institution, but on the (establishment of) an information relationship in the network in which the executive institution operates. This can include information relationships between supervisory authority and executive institution, the sharing of knowledge and information between various authorities that supervise the executive institution, but it can also include the exposure of performance of the executive institution by a supervisory authority in order to create 'checks and balances' in the organizational network of which the executive institution is a part. By exposing the performance of an executive institution, the supervisory authority mobilizes the groups of citizens who receive the services rendered by the executive institution so they can raise their voices and act as supervisory bodies themselves.

In order to make a network role possible, there should be a number of (potential) supervisory authorities that have adjacent or slightly overlapping supervisory tasks. The various supervisory authorities should experience a form of creative competition, in the sense that they are exposed to incentives urging them to deliver supervisory services of a high quality to the political principal. This implies that supervisory competition should be open to new entrants, and closed one-on-one relationships between supervisory authorities and executive institutions should be avoided (see Figure 5).

Summarizing, every role of a supervisory authority is accompanied by its own critical success factors. In a classical role, it is of the utmost importance that the legal framework (duties and responsibilities of the supervisory authority) are clear and formalized, methods of administrative supervision are documented and information relationships are clear in the sense that the information requirements of policy making bodies and supervisory authorities are systematically analyzed and implemented in information statutes and protocols. Any breach of these conditions results in political risks for the policy making body. In a modern role, it is essential that there is (a perception of) equality in the supervisory authority and the executive institution, and that both organizations respect each other's professional norms. A lack of equality and respect will result in distrust and failure in organizational learning processes. In a network role, the most important condition is that there is a network surrounding the executive institution, and that it is possible for an supervisory authority to activate either (1) other supervisory authorities or (2) groups of citizens to engage themselves with the executive institution.

\section{Administrative Supervision In Practice}

\subsection{Method}


In order to investigate how supervisory authorities use information in their daily practice and to examine how executive institutions, supervisory authorities and policy making bodies deal with information relationships, we analyzed six case studies of supervisory authorities in the Netherlands using our analytical framework consisting of roles of supervisory authorities and their respective critical success factors and risks. We analyzed three case studies based on document analysis. These were the Education Inspectorate, Social Security Supervisory Board and Center for Vehicle Technology and Information. Furthermore, we also analyzed three case studies in-depth (based on document analysis, interviews and on-site observation): the Local Residential Taxes Supervisory Authority, Inspectorate of Housing, Spatial Planning and the Environment and various supervisory authorities that supervised D efense institutions.

In the remainder of this section, we present (1) general observations and (2) problems of administrative supervision and information relationships, and categorize them under three headings: institutional problems of supervision (Section 4.2), institutional problems of information relationships (Section 4.3), and operational problems of information relationships (Section 4.4). We include illustrations and references to the empirical setting where appropriate.

\subsection{Institutional Problems of Supervision}

\subsubsection{Tension Between Roles of Cop and Coach}

In various cases, supervisory authorities attempted to mix the roles of cop and coach at the same time (Education Inspectorate, Local Residential Taxes Supervisory Authority, Inspectorate of Housing, Spatial Planning and the Environment). This resulted in hybrid constellations, and in specific problems. For example, the cases of both Local Residential Taxes Supervisory Authority and the Inspectorate of Housing, Spatial Planning and the Environment revealed that the idea of a supervisory authority, acting as a coach, appealed to municipalities. In fact, they were very enthusiastic about the idea of an supervisory authority that would help them in deciding upon appropriate levels of staff, in establishing procedures and in dealing with external software suppliers. However, municipalities were afraid that the information that they supplied to the modern supervisory authority ('coach') could be used against them in the future if the supervisory authority acted in a classical role ('as a police officer'). This anecdote shows that it is not always possible to pick various elements of supervisory roles and assemble them together in a one-sizefits-all solution.

\subsubsection{Inconsistency in Institutional Design of Administrative Supervisory}


Sometimes, organizational designs are institutionalized that are not commensurable with the role and position of the supervisory authority. In the case of the Local Residential Taxes Supervisory Authority, the formal task of the supervisory authority was to be an independent supervisory authority, operating in a more or less classical role. However, the Board of the supervisory authority consists of various representatives of the organizations under supervision, such as municipalities, local water authorities, et cetera. Obviously, the aspect of representation of various interests has taken precedence over the implementation of an organizational design that reflects an independent position for the supervisory authority.

\subsubsection{Institutional Distrust}

In general, the basis for administrative supervision is a feeling of distrust. As a result, institutionalizing administrative supervision can be regarded as institutionalizing distrust in a way that is acceptable to all parties concerned. But when the policy in a specific policy sector is very sensitive, or when relationships between various parties have become extremely polarized, the way administrative supervision has been institutionalized can be severely criticized and counterproductive competition appears. The case of the (now abolished as a result of continuous domain struggles) Social Security Supervisory Authority revealed that various amendments and continuous changes in the legislation continually fuelled the struggle between (1) supervisory authority and policy making body, and (2) supervisory authority and several executive institutions. In this specific case, the exchange of information was obstructed because of disputes over positions, duties and responsibilities of various organizations, and so forth.

\subsubsection{Catch-22}


A network role of the supervisory authority implies that supervision involves activating (by a focal supervisory authority) other supervisory authorities, by means of sharing information, or even activating citizens to raise their voices. In our case studies, the Inspectorate of Housing, Spatial Planning and the Environment issued a press communiqué to the local press in which their major findings of visits to municipalities were reported. The Education Inspectorate has published the findings of school visits on the website of the Inspectorate 0 -operation between various supervisory authorities occurred in the policy fields of social security and education. In practice, however, there is a risk that 'Catch-22' situations can emerge: the responsibility for the supervision is unclear, and organizations-under-supervision are able to play various supervisory authorities off against one another. This happened in our case study of D efense institutions, where organizations-under-supervision used contradictory information requests issued by several supervisory authorities as an excuse for failing to submit information to any supervisory authority.

\subsection{Institutional Problems of Information Relationships}

The exchange of information between various formally autonomous organizations is not always a neutral activity. Homburg has described that the exchange of information among autonomous organizations can change interdependencies between organizations, and that organizations anticipate this by carefully selecting what information to exchange, and what information not to exchange [7, 8]. In other words, administrative supervision in a way creates an arena in which not only information is exchanged, but also in which interorganizational relationships are modified and balances of power between formally autonomous organizations are affected. This notion of an arena explains why organizations are not always willing to exchange information, and why executive institutions attempt to defend their position vis-à-vis the policy making body and/ or the supervisory authority by overloading information channels (so-called 'data-wars'). We have not come across these data-wars in a strict sense in our studies, but in the cases of the Center for Vehicle Technology and Information, the Local Residential Taxes Supervisory Authority and Inspectorate of Housing, Spatial Planning and the Environment Inspectorate, there were more or less constant quarrels over what information was to be given 'away' by the organizations under supervision.

\subsection{Operational Problems of Information Relationships}

${ }^{2}$ The URL of the website is http:/ / www.onderwijsinspectie.nl 
In practice, any role of a supervisory authority has to be implemented. In some cases, we found that specific norms had not been operationalized (which is a problem in a classical role), nor was the supervisory authority willing to negotiate these norms (which is a requirement of the modern role). For example, in the case of the Inspectorate of Housing, Spatial Planning and the Environment Inspectorate, it was unclear whether the execution of the legislation was under scrutiny in the investigation of municipalities, or whether supervisory authorities were allowed to monitor the execution of tasks as a whole (including tasks like record keeping, which are not formalized in Acts).

\subsubsection{Inclusion or Exclusion of Supervision in Internal Processes}

Seen from the perspective of an organization under supervision, administrative supervision requires reaction to many information requests. If there are various supervisory authorities, it is likely that information requests will result in substantial work for executive organizations. Many organizations try to cope with this demanding supervisory environment by aligning the 'external' information requests as much as possible with internal procedures and the structure of the internal information architecture. In doing so, it can more easily cope with a variety of information requests. This way of dealing with information requests can be characterized as 'inclusion of external information requests'. A potential danger of inclusion of external information requests is that the exclusive attention decreases and that the function of supervisory authorities is hollowed out.

\section{CONCLUSIONS}

In this article, we have analyzed information relationships in the context of administrative supervision. We have demonstrated that the concept of administrative supervision is a broad one, and that it is possible to derive three roles for a supervisory authority: a classical role (the police officer metaphor), a modern role (the coach or consultant metaphor) and a network role (the networker of director metaphor). In each of the roles, information relationships bring along various sets of critical success factors. In Sections 2 and 3, a conceptual framework consisting of various critical success factors for each of the roles, was presented.

In many cases, we have seen that there is an implicit preference for a classical role for the supervisory authority. Such a role is intuitively attractive. In practice, however, many executive institutions have an institutionally anchored, relatively autonomous position, and assuming classical information relationships in these situations creates many tensions and problems. Consequently, the exchange of information is often a part of game-playing between relatively autonomous organizations, and it seems clear that information is rarely a neutral resource. Information exchange affects the positions of organizations in networks, and may be used to preserve autonomy, affect traditional dependencies, et cetera, possibly in data wars. 
In our empirical investigations, we have furthermore demonstrated that in practice, there may seem to be a deliberate strategy towards administrative supervision, but it seems to be hard to implement this strategy in the daily routines of the supervisory authority and the organization under supervision. This results in questions with respect to the operationalization of administrative supervision in information relationship, especially in the operationalization of norms and standards.

Furthermore, supervisory authorities sometimes have a somewhat vague idea of the role they are supposed to play. This may imply an organizational set up of the supervisory authority that reflects internal inconsistencies, but it may also imply inconsistencies with respect to the design and proper functioning of information relationships. These inconsistencies especially appear when classical and modern roles are mixed. In this case, there is opportunity for misuse of information, which can result in institutional distrust between supervisory authorities and executive institutions. 


\section{Literature}

[1] W.J.M. Kickert, Public M anagement and A dministrative R eform in W estern E urope, Edward Elgar, Cheltenham, 1997.

[2] C.P. Pollitt and G . Bouckaert, Public M anagement Reform (A Comparative A nalysis), Oxford University Press, Oxford, 2000.

[3] C. Hood, et al., Regulation Inside G overnment: Where New Public Management Meets the Audit Explosion, Public M oney \& M anagement, 1998, 2(18), 61-67.

[4] Ministery of the Interior, D e ministeriële verantwoordelijk heid ondersteund ( $E$ en check list voor en systematische beschrijving en analyse van toezichtsarrangementen). (Political accountability: A check list for the systematic description and analysis of supervision). 1998, Ministry of the Interior: Den Haag. p. 33-34.

[5] V.J.J.M. Bekkers, N ieuwe vormen van sturing en informatisering ( $\mathrm{N}$ ew forms of steering and informating), Eburon, Delft, 1994.

[6] V.J.J.M. Bekkers, N ew F orms of Steering and the A mbivalence of Transparency, in Public A dministration in an Information A ge, I.T.M. Snellen and W.B.H.J.v.d. D onk, Editors. 1998, IO S Press: Amsterdam.

[7] V.M.F. Homburg, The Political E conomy of Information Management (A Theoretical and E mpirical Study on the D evelopment and U se of Interorganizational Information Systems),, SO M, G roningen, 1999.

[8] V.M.F. Homburg, Politics and Property Rights In Information Exchange, Knowledge, Policy and Technology, 2000, 3(13), 13-22.

[9] M. Power, The A udit Society, Oxford University Press, Oxford, 1997.

[10] M. Wimmer, R. Traunmüller, and K. Lenk, Electronic Business Invading the Public Sector: Considerations on Change and D esign, Proceedings of the 34 th $\mathrm{H}$ awaii International $\mathrm{C}$ onference on Information Systems, 2001.

[11] B.L.W. Visser, T oezicht in bestuurlijk e rechtsverhoudingen (Supervision in administrative law), Kluwer, D eventer, 1986.

[12] P.H.H. Zeef, T ussen toezien en toezicht (B etween surveillance and control), Phaedrus, D en Haag, 1994.

[13] R.J. In 't Veld, D e verguisde staat (The dismantled state), SD U, D en Haag, 1989.

[14] H. van G unsteren, T he Q uest for C ontrol, Wiley, London, 1976.

[15] R.J. In 't Veld, M.J.W. van Twist, and M. Boogmans, Toezicht: E en kwestie van vertrouwen... (Supervision: a matter of trust), Bestad, D en Haag, 1998.

[16] M. Sparrow, The Regulatory C raft, John F.Kennedy School of G overnment, Harvard, 2000.

[17] R. Rhodes, U nderstanding G overnance, O pen University Press, Buckingham, 1997.

[18] D. de Kerckhove, G ek oppelde intelligentie (L ink ed Intelligence), SMO , Ede, 1996.

[19] Anonymous, N RC , 2001 (March 1).

[20] Netherlands Court of Audit, T oezicht op uitvoering publiek e tak en (Supervision with respect to the ex eaution of public tasks), Tweede Kamer TK 25956 nrs. 1-2, D en Haag, 1997. 


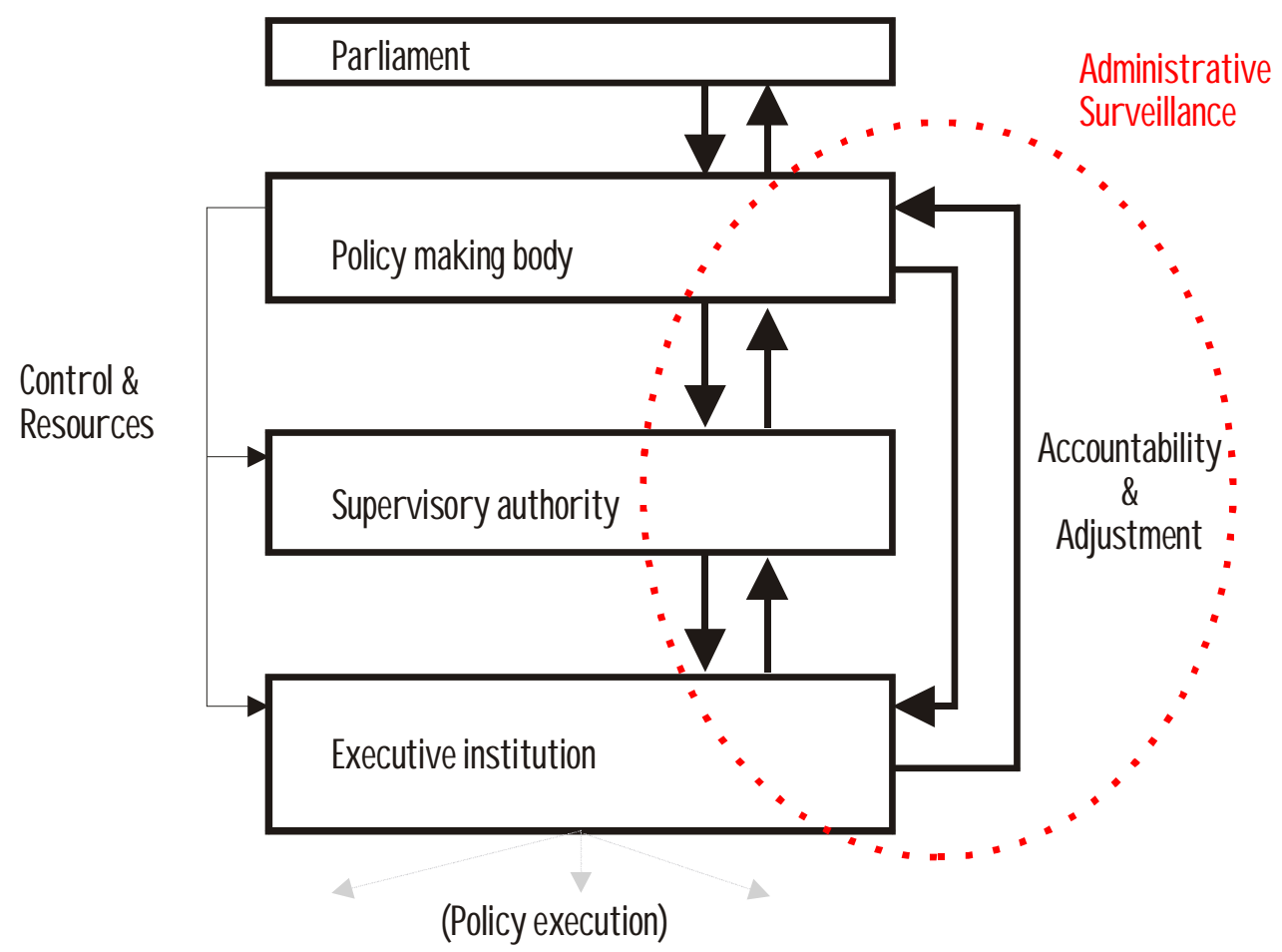

Figure 1: Policy making bodies, supervisory authority and executive institutions (adapted from [20]) 


\begin{tabular}{|l|l|l|l|}
\hline Steering & Classical & Modern & Network \\
\hline Division of labour & $\begin{array}{l}\text { Unicentric } \\
\text { Separated tasks } \\
\text { between supervisor } \\
\text { and executive } \\
\text { institution; } \\
\text { supervision by } \\
\text { screening }\end{array}$ & $\begin{array}{l}\text { Intertwined tasks } \\
\text { between supervisor } \\
\text { and executive } \\
\text { institution; } \\
\text { supervision by } \\
\text { steering }\end{array}$ & $\begin{array}{l}\text { Various supervisors } \\
\text { on adjacent or } \\
\text { overlapping areas; } \\
\text { supervision by } \\
\text { directing, and } \\
\text { activating third } \\
\text { parties }\end{array}$ \\
\hline Metaphor & Cop / Police-officer & Coach & Director \\
\hline Norms & $\begin{array}{l}\text { Static; based on } \\
\text { Acts and laws; } \\
\text { procedural }\end{array}$ & $\begin{array}{l}\text { Dynamic; based on } \\
\text { common interests; } \\
\text { substantial }\end{array}$ & Dynamic \\
\hline Sanctioning & Repressive & Preventive & $\begin{array}{l}\text { Exposure; 'naming } \\
\text { \& shaming' }\end{array}$ \\
\hline Learning & Single loop & Double Loop & Learning by linking \\
\hline
\end{tabular}

Figure 2: Summary of roles of supervisory authorities 


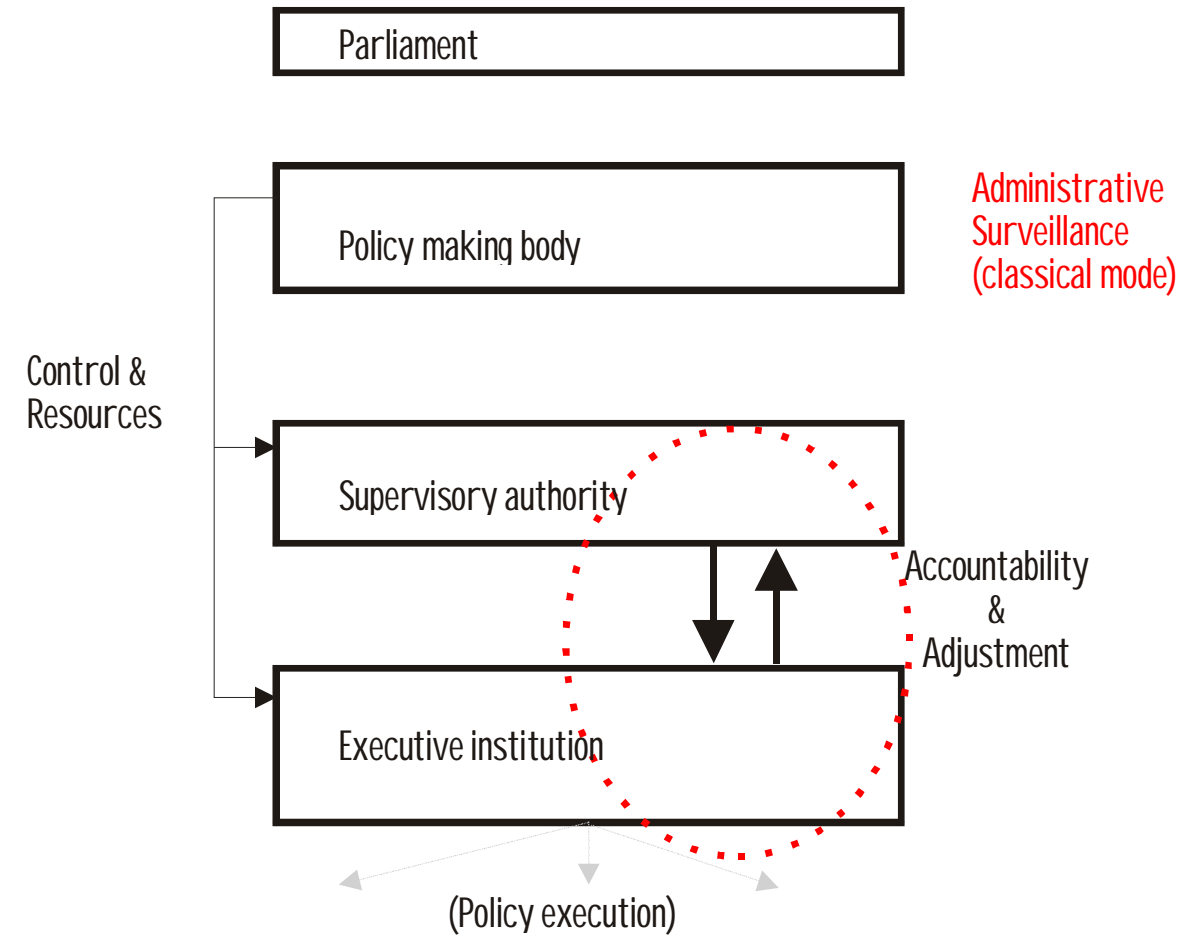

Figure 3: Classical role for supervisory authority 

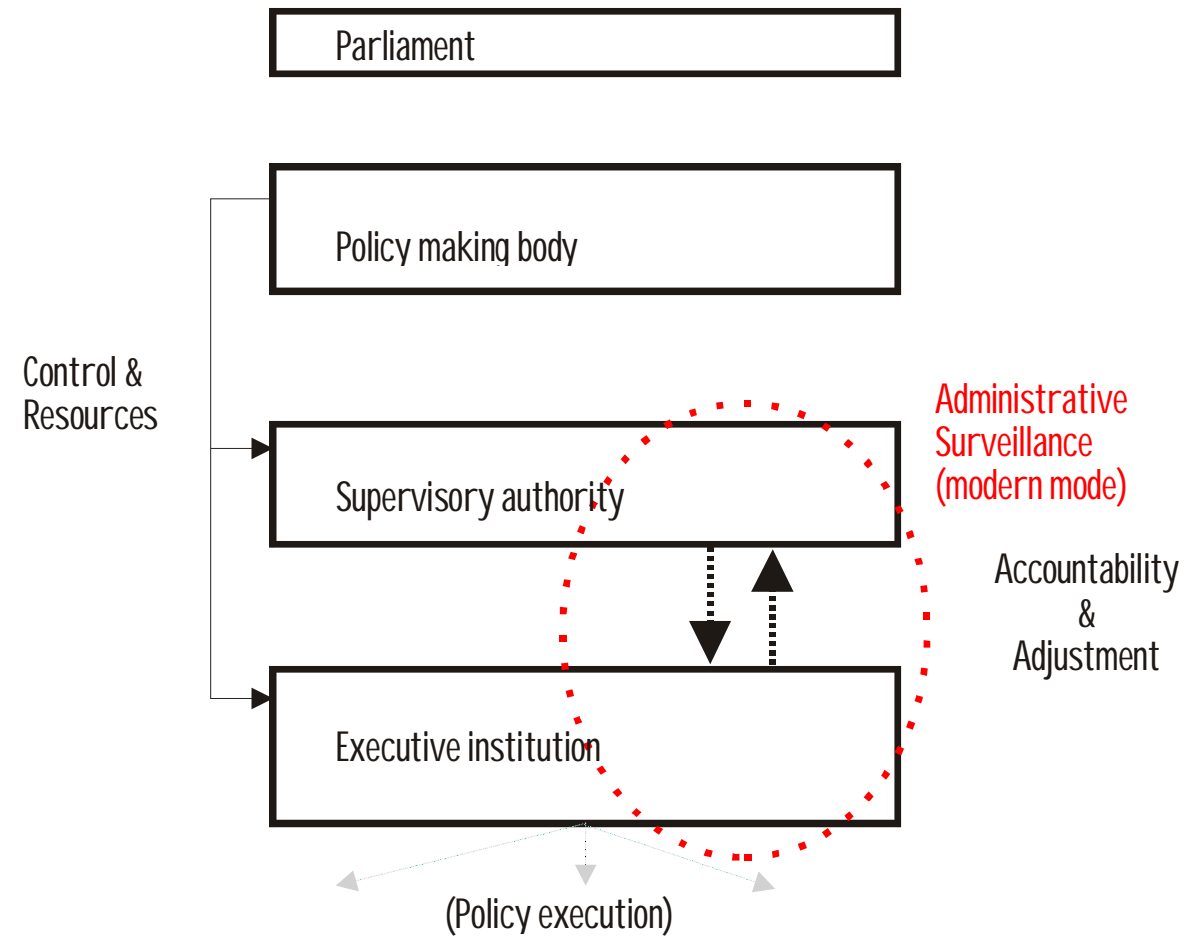

Figure 4: Modern role for supervisory authority 


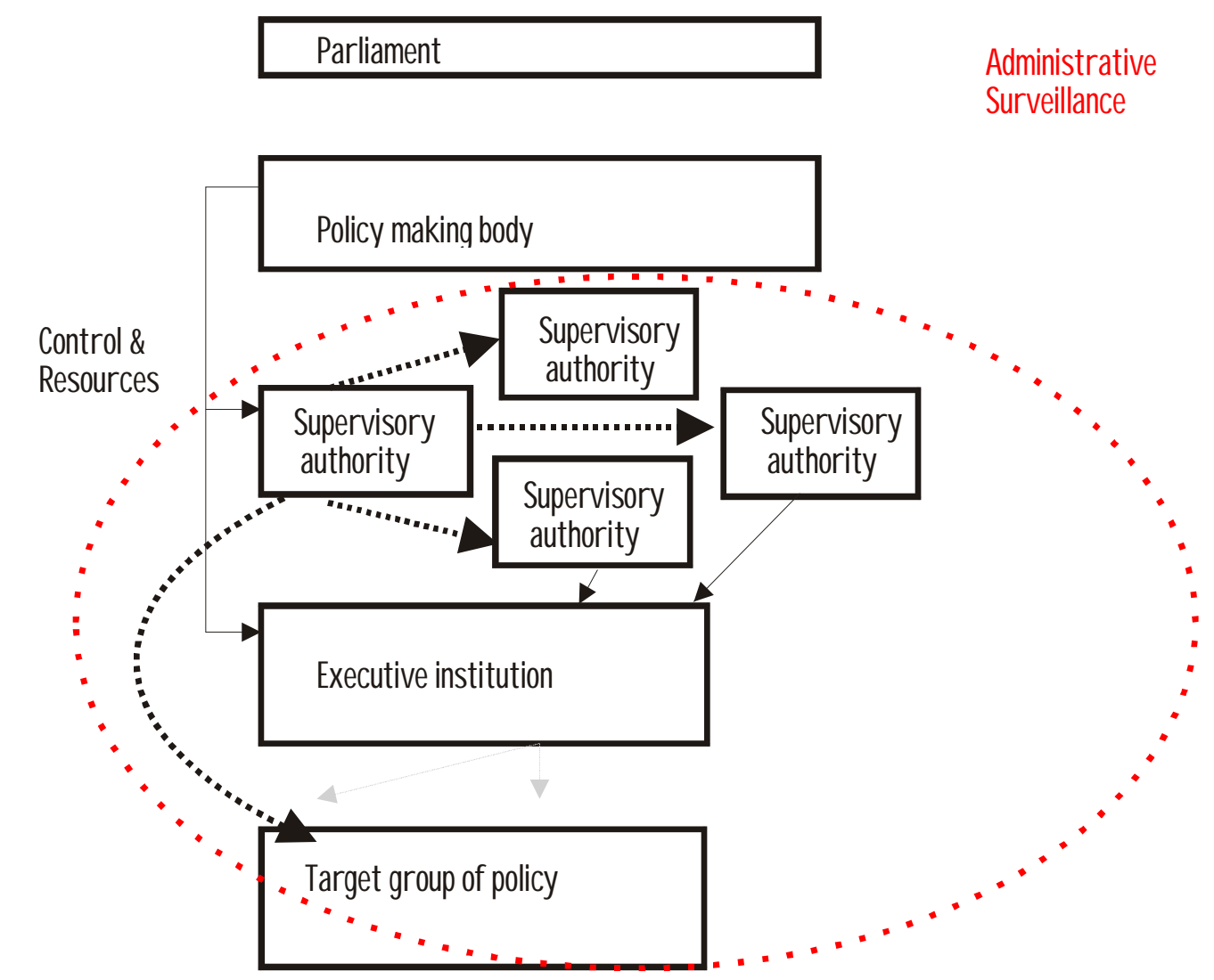

Figure 5: Modern role for supervisory authority 